\title{
Detection of campylobacter by immunofluorescence in stools and rectal biopsies of patients with diarrhoea
}

\author{
AB PRICE, JEAN M DOLBY, PR DUNSCOMBE, JENNIFER STIRLING \\ From the Clinical Research Centre and Northwick Park Hospital, Watford Road, Harrow HA1 $3 U J$
}

SUMMARY Rabbit antiserum, elicited by the intravenous injection of a strain of Campylobacter jejuni heated to $100^{\circ} \mathrm{C}$, cross reacted strongly with all other thermophilic campylobacters tested as well as with "C pyloridis" and could be detected by indirect fluorescence with labelled antirabbit serum. Antisera to formalin killed cells did not do so. The correlation of positive stool culture with positive immunofluorescence of stools and rectal biopsies from patients with diarrhoea was 70-80\%. Some inconsistent, weak reactions showing differently shaped organisms have been seen with some strains of Bacteroides fragilis. Wolinella spp reacted weakly, but one strain of Vibrio cholerae tested did not. Other intestinal organisms, commensals, and pathogens tested were negative.

Although Campylobacter jejuni/coli can now be isolated easily from stools $^{1-3}$ and distinguished biochemically, ${ }^{45}$ the pathogenesis of human intestinal infection is still not established. For example, it is still not clear if in human disease a toxin is responsible or whether the organisms are enteroinvasive.$^{6-8}$ To investigate the latter, and as a possible rapid diagnostic test for $C$ jejuni/coli, we attempted to develop a labelled antibody for use on rectal biopsy material.

Current methods of direct microscopy of stools such as phase contrast, ${ }^{9}$ dark field, ${ }^{10}$ and Gram staining," have shown a $60-70 \%$ correlation with positive stool culture and a $95 \%$ correlation ${ }^{12}$ using aqueous basic fuchsin. These methods, however, are not applicable to biopsy tissue.

The specificity of the $\mathrm{O}, \mathrm{H}$, and other antigens of campylobacter ${ }^{13-15}$ and the antibodies they elicit ${ }^{16-17}$ will limit the usefulness of serological detection unless a common antigen exists. Immunofluorescence has been successfully used with convalescent patients' sera and autologous strains heated to $100^{\circ} \mathrm{C} .{ }^{18}$ Watson and Kerr, ${ }^{19}$ using three selected strains of $C$ jejuni heated to $100^{\circ} \mathrm{C}$, managed to produce a "common antigen pool" and were then able to detect $80 \%$ of $C$ jejuni infections serologically by indirect immunofluorescence. Similar evidence of shared antigens has been shown by Lambe and Ferguson ${ }^{20}$; fluorescein conjugated antibodies to two selected strains of $C$ jejuni were used

Accepted for publication 30 May 1984 but the strains were formalinised, not heated.

We have evaluated, on stool and biopsy material, the experimental and clinical use of rabbit antiserum to a heat stable antigen of $C$ jejuni common to a series of $C$ jejuni/coli.

\section{Material and methods}

The study conveniently divides into two parts: (a) the production and specificity of the antisera and their use in indirect fluorescence tests for the detection of campylobacter either as pure cultures or when experimentally added to stools; and (b) the detection of campylobacter in stools and rectal biopsies of patients with diarrhoea, using a selected, standard antiserum.

\section{(a) PRODUCTION, SPECIFICITY, AND USE OF ANTISERA}

\section{Cultures}

Sixteen clinical isolates of $C$ jejuni and one of $C$ coli. cultured on selective $\operatorname{agar}^{1}$ at $42^{\circ} \mathrm{C}$, were collected over a two year period from patients with diarrhoea admitted to the hospital infectious diseases unit or from patients referred to the outpatients department. Reference strains used were from the National (UK) Collection of Type Cultures (The Curator, Central Public Health Laboratory, Colindale, London, NW7 5HT) and comprised: $C$ coli, NCTC 11353; $C$ fetus, NCTC 10842; and $C$ laridis 
NCTC 11352. "C pyloridis" was cultured from gastric antrum biopsies. ${ }^{21}$ All of these strains were used either in the preparation of antisera or in serological testing. The strain of $C$ jejuni finally chosen to prepare our standard antiserum (M53729/80) has been accepted by the National Collection and designated NCTC 11626. Besides campylobacter, other enteric organisms, including pathogens, were tested against this antiserum.

The campylobacter strains were subcultured weekly on blood-agar plates, which were incubated at $37^{\circ} \mathrm{C}$ for $24 \mathrm{~h}$ (or four days for " $C$ pyloridis") in anaerobic jars without catalysts from which two thirds of the air was extracted and replaced by a mixture of $10 \% \mathrm{CO}_{2}, 10 \% \mathrm{H}_{2}$, and $80 \% \mathrm{~N}_{2}$. They were then stored in anaerobic jars in the reduced oxygen-gas mixture at room temperature until the next subculture. Bacterial growth harvested from overnight blood-agar plates into $10 \%$ glycerol-broth transport medium and stored at $-30^{\circ} \mathrm{C}$ remained viable for over a year.

\section{Rabbit vaccines}

Initially, two strains of $C$ jejuni were selected at random for vaccine preparation; later on four other serotypes were tested for confirmation. Two methods of preparation of the vaccine were used: in one, organisms were killed by heating to $100^{\circ} \mathrm{C}$ and in the other formalin was used. The chosen strains of $C$ jejuni, grown for $24-48 \mathrm{~h}$ at $37^{\circ} \mathrm{C}$ on blood-agar plates, were either harvested into phosphate buffered saline (PBS), washed once, resuspended, held in a boiling water bath for $1 \mathrm{~h}$, and washed and resuspended again in PBS; or were harvested into $0.5 \%$ formol-saline, held at $4^{\circ} \mathrm{C}$ for two days, and washed and resuspended in PBS. All vaccine suspensions were adjusted to an opacity of 10 international opacity units (IOU), equivalent to about $2 \times$ $10^{9}$ organisms per millilitre.

\section{Preparation of antisera}

New Zealand White adult rabbits were given 9-10 doses of vaccine suspension intravenously over five to six weeks. Initially, injections were at three to four day intervals beginning with $0.2 \mathrm{ml}$ and increasing to $1 \mathrm{ml}$ and then two final weekly injections of 1 and $2 \mathrm{ml}$ volumes were given. Animals were bled two weeks after the last dose. The serum samples were separated and heated at $56^{\circ} \mathrm{C}$ for $30 \mathrm{~min}$.

\section{Agglutination tests}

$\mathrm{O}$ and $\mathrm{H}$ agglutination tests were performed. Washed bacterial suspensions were made from $24 \mathrm{~h}$ $37^{\circ} \mathrm{C}$ cultures, which were killed either by heating to $100^{\circ} \mathrm{C}$ for $1 \mathrm{~h}$ or by suspending in $0.5 \%$ formolsaline for two days at $4^{\circ} \mathrm{C}$. Bacteria were then washed and resuspended in PBS. Suspensions were adjusted to an opacity of $10 \mathrm{IOU}$. Serial twofold dilutions of antisera were mixed with equal volumes of bacterial suspension in Dreyer's tubes. Agglutination of formol-saline killed suspensions was carried out for $4 \mathrm{~h}$ at $37^{\circ} \mathrm{C}$; the mixture was left overnight at room temperature $(\mathrm{H})$ before reading. Agglutination of specimens killed by heating to $100^{\circ} \mathrm{C}$ was carried out at $50^{\circ} \mathrm{C}$ in a water bath overnight and read immediately $(\mathrm{O})$. Agglutination was detected with a hand lens, and the antiserum titre was expressed as the highest dilution giving agglutination.

\section{Passive haemagglutination}

The test determining $\mathrm{O}$ antibody was as described by Penner and Hennessey..$^{13}$ Sheep red blood cells were sensitised with the supernatants of boiled suspensions of bacteria in saline. Serial doubling dilutions of antisera were incubated with equal volumes of washed $0.5 \%$ suspension of sensitised red blood cells in U-wells of microtitre trays (Sterilin Ltd, Teddington, Middlesex) for $1 \mathrm{~h}$ at $37^{\circ} \mathrm{C}$. Trays were examined after being held overnight at $4^{\circ} \mathrm{C}$. The antiserum titre was expressed as the highest dilution causing $50 \%$ agglutination, judged by eye.

Preparation of bacterial cultures for immunofuorescence

The standard procedure for preparation was to take organisms from one to two day blood-agar plates, wash in PBS, heat to $63^{\circ} \mathrm{C}$ for $45 \mathrm{~min}$, wash again, and standardise by opacity (see below). The prepared bacterial suspensions were spread on to microscope slides with a $4 \mathrm{~mm}$ diameter bacteriological loop. The slides were air dried and fixed with acetone for $20 \mathrm{~min}^{18}$ Three other methods of preparation of slides were tested: first, using untreated organisms in which the suspensions were washed twice in PBS only; secondly, using organisms heated to $100^{\circ} \mathrm{C}$ for $1 \mathrm{~h}$, washed, and then resuspended in PBS; and, thirdly, using organisms held in $0.5 \%$ formol-saline for two days at $4^{\circ} \mathrm{C}$ and washed twice in PBS. As previously, all slides were air dried and fixed in acetone for $20 \mathrm{~min}$. A few slides were prepared without acetone treatment by drying in air and then treating the slides with $10 \%$ formol-saline for $1 \mathrm{~h}$, rinsing, and air drying again.

All suspensions were initially made to an opacity of 5 IOU, and were then diluted $1 / 10-1 / 20$ to give 1 $\times 10^{8}-5 \times 10^{7}$ organisms per millilitre, from which the slide smears were made. The suspensions were used immediately; if stored it was usually necessary to rewash once or twice (to remove blocking antigen in the supernatant) and to resuspend in PBS. Prepared slides were stable for several weeks. 
Preparation of stools for immunofuorescence Experiments to determine the sensitivity of the immunofluorescence system for detecting campylobacter in stools were carried out on normal stool suspensions to which serial dilutions of campylobacter had been added. Stool specimens with or without added campylobacter were homogenised in saline (about 10\% wt/vol). The suspensions were either allowed to settle for $1 \frac{1 / 2}{2}-2 \mathrm{~h}$ on the bench or centrifuged briefly; the supernatant was heated at $62^{\circ} \mathrm{C}$ for $30 \mathrm{~min}$. Slides were prepared by loop from the supernatant and from 1/10 saline dilutions, air dried, and fixed in acetone as for the preparation of slides from pure bacterial cultures. For comparison, slides were also prepared from similar dilutions of campylobacter alone.

\section{Immunofuorescence technique}

Slides were washed in PBS and layered with $1 / 500$ standard antiserum (or predetermined dilutions of other antisera). The standard antiserum was prepared to $C$ jejuni strain M53729/80 (NCTC 11626). After 30 min slides were washed three times in PBS, treated with $1 / 30$ swine antirabbit fluorescein conjugated serum (Dako-immunoglobulins, Copenhagen) for a further $30 \mathrm{~min}$, and washed again. They were mounted in PBS and glycerol (50:50) and examined for fluorescence using a Zeiss microscope. Known positive and negative culture controls were stained on each occasion, together with a preparation from which the first layer (the antiserum) was omitted.

(b) CLINICAL MATERIAL

Preparation of stools from patients for immunofluorescence

Stool specimens from 28 patients with diarrhoea were selected by one of us (JS) to give roughly equal numbers of campylobacter culture positive and culture negative stools. Smears were prepared as above within three days of collection and stored at $4^{\circ} \mathrm{C}$. Then, without knowledge of the culture results, they were examined by fluorescence microscopy (by ABP and PRD).
Preparation and examination of biopsy tissue for immunofuorescence and light microscopy

Rectal biopsies were taken within $48 \mathrm{~h}$ of admission from another 25 patients admitted to the hospital infectious diseases unit with a presumptive clinical diagnosis of infective diarrhoea. In most cases two specimens were taken; if only one was obtained, it was divided. One of the two was processed by routine methods to a paraffin block, from which 3 $\mu \mathrm{m}$ sections were stained with haematoxylin and eosin. The second sample was flash frozen using isopentane liquid nitrogen and stored at $-70^{\circ} \mathrm{C}$ until sectioned for fluorescence microscopy. These sections were then fixed in acetone for $20 \mathrm{~min}$ and treated as previously described.

The routine paraffin embedded sections were examined and classified into the following categories: normal, oedematous, mild active proctitis, typical infective proctitis, chronic inflammation, pseudomembranous colitis, ulcerative colitis, and Crohn's disease. These categories are based on accepted criteria outlined in published work. ${ }^{22}$

\section{Results}

\section{(a) SEROLOGICAL SPECIFICITY OF ANTISERA AND SENSITIVITY OF THE INDIRECT IMMUNOFLUORESCENCE TEST FOR CAMPYLOBACTER IN STOOLS}

Serological reactions with rabbit antisera

The agglutinins present in the antisera to two clinical isolates formalinised or heated to $100^{\circ} \mathrm{C}$ are recorded in Table 1. The results show high titres to homologous vaccine but some cross reactions. The comparison of agglutinating and haemagglutinating titres of the antisera to one strain for several other strains is shown in Table 2 . Sera to the other vaccine strain behaved similarly, except that there were fewer cross agglutinations. Passive haemagglutination was strain (serotype) specific, whereas the agglutination suspensions heated to $100^{\circ} \mathrm{C}$ was less specific.

Antisera to these two strains prepared in two ways

Table 1 Agglutinin titres of rabbit antisera to C jejuni strains 34640 and 53729

\begin{tabular}{|c|c|c|c|c|c|}
\hline \multirow[t]{2}{*}{ Antisera to } & & \multicolumn{4}{|c|}{ Inverse titres against suspensions } \\
\hline & & $34640 / F S$ & $34640 / 100$ & 53729/FS & $53729 / 100$ \\
\hline $\begin{array}{l}34640 \\
34640\end{array}$ & $\begin{array}{l}\mathrm{FS}^{*} \\
100^{\dagger}\end{array}$ & $\begin{array}{r}2000 \\
500\end{array}$ & $\begin{array}{r}100 \\
2000\end{array}$ & $\begin{array}{l}<20 \\
<20\end{array}$ & $\begin{array}{l}20 \\
20\end{array}$ \\
\hline $\begin{array}{l}53729 \\
53729\end{array}$ & $\begin{array}{l}\text { FS } \\
100\end{array}$ & $\begin{array}{l}(100) \\
(500)\end{array}$ & $\begin{array}{l}<20 \\
100\end{array}$ & $\begin{array}{r}2000 \\
100\end{array}$ & $\begin{array}{l}100 \\
500\end{array}$ \\
\hline
\end{tabular}

Figures in parentheses indicate weak agglutination.

* Bacteria killed with formol-saline.

†Bacteria heated to $100^{\circ} \mathrm{C}$ for $1 \mathrm{~h}$. 
Table 2 Agglutinin, haemagglutinin, and immunoftuorescence of campylobacter antisera to M53729/80

\begin{tabular}{|c|c|c|c|c|c|c|c|c|}
\hline \multirow[t]{3}{*}{ Test suspension } & \multicolumn{4}{|c|}{ Antisera to FS-53729 } & \multicolumn{4}{|c|}{ Antisera to $100^{\circ} \mathrm{C}-53729$} \\
\hline & \multicolumn{2}{|l|}{ Agg } & \multirow[t]{2}{*}{ Haem } & \multirow[t]{2}{*}{$I F$} & \multicolumn{2}{|l|}{ Agg } & \multirow[t]{2}{*}{ Haem } & \multirow[t]{2}{*}{ IF } \\
\hline & $F S$ & 100 & & & $F S$ & 100 & & \\
\hline $\begin{array}{l}\text { Homologous } C \text { jejuni I } \\
\text { Heterologous } C \text { jejuni I } \\
C \text { jejuni II } \\
C \text { coli }\end{array}$ & $\begin{array}{l}+ \\
( \pm) \\
- \\
-\end{array}$ & $\begin{array}{l} \pm \\
- \\
\pm \\
-\end{array}$ & $\begin{array}{l}++ \\
- \\
- \\
-\end{array}$ & $\begin{array}{l}+ \\
- \\
( \pm)\end{array}$ & $\begin{array}{l} \pm \\
( \pm) \\
- \\
-\end{array}$ & $\begin{array}{l}+ \\
( \pm) \\
\pm \\
( \pm)\end{array}$ & $\begin{array}{l}++ \\
- \\
- \\
-\end{array}$ & $\begin{array}{l}++ \\
+ \\
+ \\
+\end{array}$ \\
\hline
\end{tabular}

Agg = agglutinin; haem = haemagglutinin; IF = immunofluorescence

For other abbreviations see Table 1 .

was next tried in indirect immunofluorescence testing against a homologous and other campylobacters prepared by the standard procedure. The results of the immunofluorescence tests are also given in Table 2. They are striking in that strong positives were recorded with all the strains of $C$ jejuni and $C$ coli tested against the antiserum to $100^{\circ} \mathrm{C}$ heated organisms but not to the formalin killed bacteria. The antiserum to the strain M53729/80 was stronger than other antisera tested, and this strain has been selected as the one of choice for preparing standard antisera.

Antisera to $100^{\circ} \mathrm{C}$ heated organisms also fluoresced with untreated organisms, organisms killed with formalin, and with preparations not fixed with acetone.

In all, about 40 strains of thermophilic campylobacters, including three strains of $C$ coli, have been collected and tested for immunofluorescence with the standard antiserum over a period of two years; all have been strongly positive with the standard antiserum. $C$ fetus strains have given only weak reactions quite distinct in appearance from $C$ jejuni/ coli. One strain of $C$ laridis and six isolates of " $C$ pyloridis" were positive. Of other organisms, two strains of Bacteroides fragilis fluoresced slightly (it was impossible to absorb this out with bacterial suspension and it was not a consistent finding). These fluorescing organisms, being morphologically different from campylobacter, have not been mistaken for them in identifying specific campylobacter reactions. Wolinella spp reacted slightly, but tests with one strain each of Vibrio cholerae, Escherichia coli, Salmonella sp, and Streptococcus faecalis were not fluorescent. Troublesome fluorescence of culture negative (for campylobacter) stools was rare, which indicates that cross reactions with normal gut flora are not a problem. Fluorescing campylobacters are illustrated in Fig. 1a.

Immunofluorescence of strains of $C$ jejuni, $C$ coli, and $C$ laridis to antisera prepared to strains of these species is shown in Table 3 . There was positive cross immunofluorescence for all, being strongest with the homologous antisera. E coli did not fluoresce.

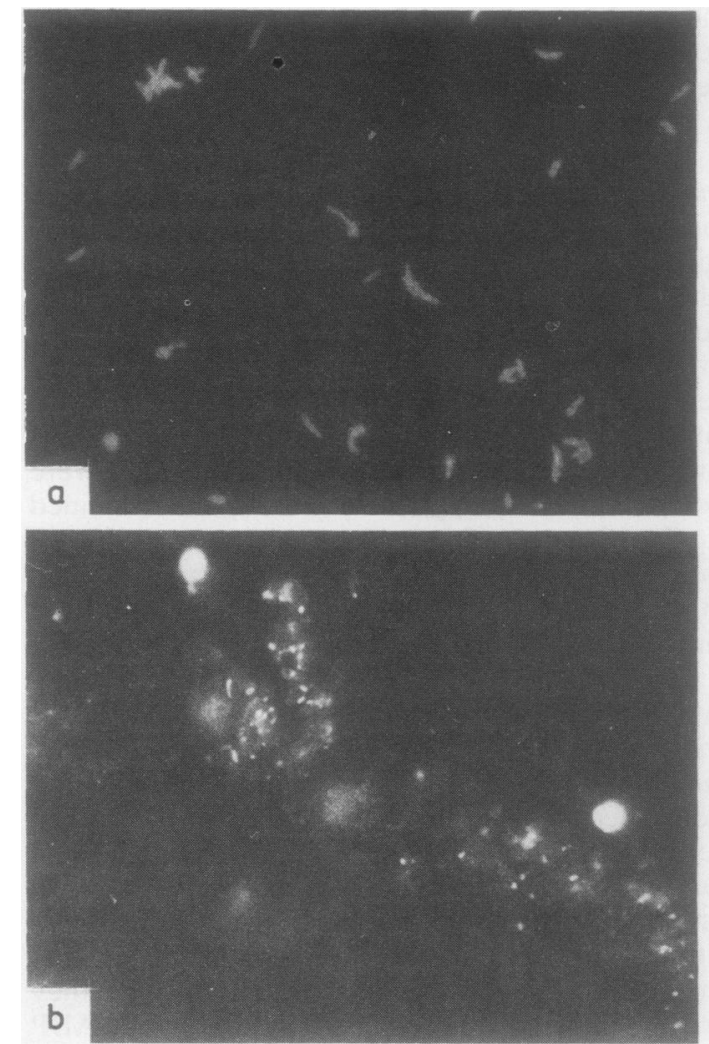

Fig. 1 Preparations were treated with rabbit anti-M53729/80 and fuorescein conjugated swine antirabbit serum. (a) Fluorescing $C$ jejuni in pure culture. $\times$ 1950. (b) Fluorescing campylobacter in a rectal biopsy. The organisms are seen aligned over the surface epithelium in debris and mucus. $\times 780$.

Immunofluorescence of campylobacters in stools When the fluorescence of serial dilutions of pure cultures were compared with similar numbers of organisms added to normal stools we could detect fluorescence in the pure cultures at $10^{5}$ organisms per millilitre, but in the stool preparations $10^{6}$ organisms per millilitre were required. 
Table 3 Cross immunoftuorescence (IF) of campylobacter

\begin{tabular}{lllll}
\hline Antiserum to & \multicolumn{5}{l}{ IF with strain } \\
\cline { 2 - 5 } & 53729 & 54601 & 11782 & NCTC \\
& & & & 11352 \\
\hline C jejuni I strain 53729 & ++ & + & + & \pm \\
C jejuni II strain 54601 & + & ++ & + & \pm \\
C coli strain 11782 & + & + & + & \pm \\
C laridis NCTC 11352 & + & \pm & \pm & ++ \\
\hline
\end{tabular}

The detection of campylobacters in stool specimens from patients from whom $C$ jejuni could be grown was comparatively easy both on brightness of fluorescence and the shape of the fluorescing organisms. Some specimens showed a considerable amount of weak background fluorescence, but with practice this could be distinguished from the immunofluorescence due to campylobacters.

(b) IMMUNOFLUORESCENCE OF CAMPYLOBACTERS IN STOOLS AND RECTAL BIOPSIES FROM PATIENTS

Comparison of campylobacter detection in stools from patients by microbial culture and immunofluorescence

A comparison was made on the stools of 28 patients selected to give a cross section of pathogens including campylobacters. The immunofluorescence detection was carried out without knowledge of culture results. All the campylobacter cultures isolated were tested as pure cultures for the existence of positive immunofluorescence with our standard antiserum and were positive in all. Fig. 2 shows the immunofluorescence and culture results of specimens from the 28 patients, comprising 11 culture positive and 17 culture negative specimens; the correlation of the two methods was encouraging. Campylobacter was, however, detected in six culture negative specimens. Four of these six patients were receiving antibiotics; for the other two patients records were not available. We failed to pick up campylobacter in three of 11 culture positive stools.

At worst, fluorescence correlated with culture results in $19 / 28$ specimens $(62 \%)$. If we assume that dead or dying organisms were detected by fluorescence in the four patients taking antibiotics then detection rises to $82 \%$.

Comparison of campylobacter detection in rectal biopsies by microbial stool culture and immunofluorescence of tissue

Rectal biopsy tissue from another 25 patients from whom stools were cultured was examined in a similar way. The results show a good correlation with the isolation of campylobacter (Fig. 3). One culture positive biopsy was missed and four biopsies

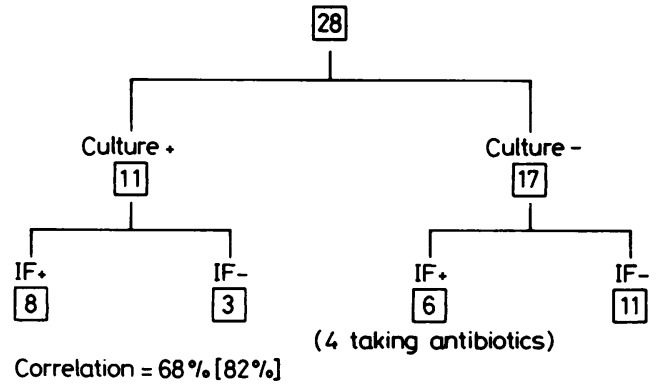

Fig. 2 Stools: correlation of culture and immunofluorescence (IF). Correlation is given as a percentage of stools and specimens from 28 patients. Percentage excluding known anomalies is given in parentheses.

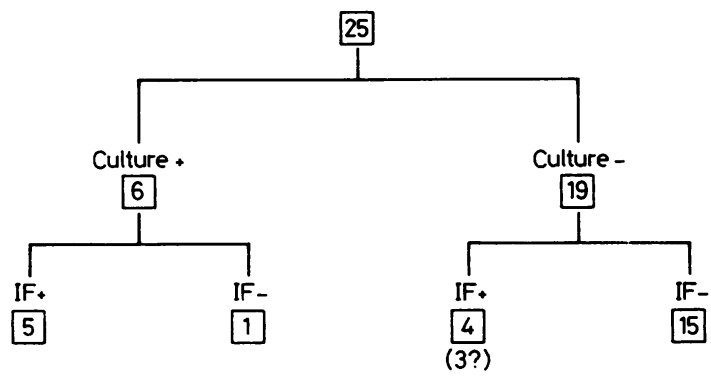

Correlation $=80 \%$

Fig. 3 Rectal biopsies: correlation of stool culture and immunofuorescence (IF) of tissue. Correlation is given as a percentage of biopsies from 25 patients. Correlations are as in Fig. 2.

fluoresced in patients from whom campylobacter could not be isolated. Of these four, three gave a rather weak reaction, but the fourth fluoresced strongly. The correlation of fluorescence and culture was $80 \%$.

All the fluorescent organisms were observed on the surface of the biopsies either close to the surface epithelial cell or caught up in overlying debris. No fluorescence, other than background, was seen in the mucosa (Fig. 1b).

\section{Light microscopy of the biopsies}

The histopathology of the rectal biopsies alongside the immunofluorescence of the biopsies and the microbiological findings on stool culture are given in Table 4.

Five of the six biopsies ( $88 \%$ ) from patients from whom $C$ jejuni was isolated had a morphology typical of infection and a positive immunofluorescence result. By contrast, in the campylobacter negative group, although fluorescence was positive in four specimens, none of these had the light microscopical appearances of typical infective proctitis. 
Table 4 Pathology and immunoftuorescence (IF) of biopsy tissue with microbiological culture of stools for pathogens

\begin{tabular}{|c|c|c|c|c|}
\hline \multirow[t]{2}{*}{ Biopsy category } & \multicolumn{2}{|c|}{ Biopsy positive IF } & \multicolumn{2}{|c|}{ Biopsy negative IF } \\
\hline & No & Pathogen & No & Pathogen \\
\hline Normal & 1 & None & $\begin{array}{l}9 \\
1\end{array}$ & $\begin{array}{l}\text { None } \\
\text { Campylobacter jejuni }\end{array}$ \\
\hline $\begin{array}{l}\text { Oedema } \\
\text { Mild active proctitis } \\
\text { Typical infective proctitis }\end{array}$ & $\begin{array}{l}1 \\
1 \\
5\end{array}$ & $\begin{array}{l}\text { None } \\
\text { None } \\
C \text { jejuni }\end{array}$ & $\begin{array}{l}1 \\
1 \\
1\end{array}$ & $\begin{array}{l}\text { None } \\
\text { Salmonella typhi } \\
\text { S typhi }\end{array}$ \\
\hline Ulcerative colitis & 1 & None & $\begin{array}{l}1 \\
1 \\
1\end{array}$ & $\begin{array}{l}\text { Shigella flexnent } \\
\text { S typhi } \\
\text { None }\end{array}$ \\
\hline
\end{tabular}

\section{Discussion}

Fluorescent microscopy on both stool and biopsy specimens provides results more rapidly than microbiological culture. The correlation of immunofluorescence with culture results, both in tissue and stool preparation, was certainly equal to or better than other published methods of direct microscopy on stools, except the use of basic fuchsin. ${ }^{12}$ In the current study of biopsies (Fig. 3) the level of false positive and negative results was below $10 \%$ if one excludes equivocal results and cases in which administration of antibiotics before culture may have confused the issue. The main use of immunofluorescence in the clinical situation would seem to be as a guide in those patients thought to have bacterial diarrhoea but in whom stool culture is negative. This is still a problem in up to half of the clinically suspected cases. ${ }^{22}$

The results in Table 4 suggest that the combination of a typical "infective" biopsy and an unequivocally positive immunofluorescence test for campylobacter is indeed a reliable guide to the cause of the infection. Previous results from our laboratory showed that the correlation of campylobacter isolation and a typical infective picture in a rectal biopsy was greater than $90 \% .^{22}$ These results and those of Table 4 together make us confident that the pick up figure of $5 / 6(88 \%)$ by biopsy appearance and immunofluorescence results only is realistic.

Positive fluorescence of organisms in all biopsy specimens was limited to the surface either in close apposition to the epithelium or within the overlying surface debris. This implies that in the pathogenesis of campylobacter infection either invasion of the mucosa does not occur or it occurs in numbers too small for detection by this technique. The histological changes in the mucosa in campylobacter infection are indistinguishable from those seen in shigellosis and salmonellosis, both shown to be invasive organisms. ${ }^{23}{ }^{24}$ Attempts to show invasion by campylobacter in culture and in animal models has produced conflicting results. ${ }^{6}$ The cryptal damage and polymorph reaction seen in the rectal mucosa would favour invasion; if damage was due solely to a toxin it might be expected to be minimal by analogy with cholera toxin. If direct microscopy is to be used as evidence against the invasive potential of campylobacters, however, we believe that it is important to improve the sensitivity of the method.

The nature of the common antigen involved in immunofluorescence has not been investigated in detail, but sharing of antigens in campylobacters has been amply demonstrated. ${ }^{17}$ The stability to $100^{\circ} \mathrm{C}$ suggested that the antigen utilised here may be of lipopolysaccharide nature other than the type specific $O$. Logan and Trust ${ }^{25}$ and Naess and Hofstad $^{26}$ have shown that the lipopolysaccharide in $C$ jejuni/coli is of low molecular weight, lacking long $\mathrm{O}$ antigenic side chains and having a common core lipid $\mathrm{A}$. The $\mathrm{O}$ specificity is determined by the sugar attached, but the core lipid $\mathrm{A}$ is less protected and more likely to react with antibody than the $\mathrm{O}$ antigens of the Enterobacteriaceae; it has similarities with the core lipids of $E$ coli and $B$ fragilis.

Preliminary absorption experiments by standard techniques confirm that antibody to a common antigen is responsible for immunofluorescence, reinforced by immunofluorescence due to its $\mathrm{O}$ antigen and specific serotype antibody. While $E$ coli did not fluoresce with campylobacter antiserum, absorption of the serum with $E$ coli removed all but the serotype specific fluorescence, and absorption with $B$ fragilis decreased the non-O fluorescence. Preliminary observations suggest that core lipid may be implicated (Dolby, unpublished observations).

Recently, Rautelin and Kosunen ${ }^{27}$ have extracted a thermostable "common antigen" from $C$ jejunil coli by means of acid glycine. This has been confirmed by Logan and Trust $^{28}$ and characterised as a $31 \mathrm{~K}$ protein. It is another candidate for the antigen which we are utilising in our immunofluorescence test.

The immunofluorescence which we have described is different from that detected with patients' serum and the patients' own organisms, in which antisera to unheated organisms are concerned.$^{18}$ It is also different from that reported by 
Watson and Kerr, ${ }^{19}$ in which the patients' antibodies to unheated organisms react with three selected strains containing "common" heat stable agglutinogens. Unlike Lambe and Ferguson ${ }^{20}$ we have been unable to detect a common antigen using antiserum to formalinised suspensions.

The two strains used to elicit the antisera on which most of this work has been based were not typed against standard sera, but by cross agglutinations with their antisera they were shown to be of different serotype ( $\mathrm{O}$ and $\mathrm{H}$ antigens). They have been fully investigated; five other strains less fully investigated gave apparently similar results which were independent of serotype. It is of interest that " $C$ pyloridis," isolated from gastric antral tissue, ${ }^{29} 21$ fluoresces strongly as well as the thermophilic campylobacters $C$ jejuni, $C$ coli, and $C$ laridis and may be detectable in biopsy materials.

The ability of pure cultures to fluoresce with the antiserum raised to $100^{\circ} \mathrm{C}$ heated organisms is influenced either by the degree of washing of the test organism or the degree of lysis on storage. The inability of our stock suspensions to fluoresce after storage may be due to blockage of antiserum attachment by DNA, which is reported as responsible for autoagglutination reactions in stored suspensions. ${ }^{30}$ Suspensions of $C$ jejuni M53729 (NCTC 11626), to which we raised our standard antiserum, are, however, more stable than many of the other strains tested. This may be the reason for its successful use in this immunofluorescence method. Purification of a common antigen would, however, remove the necessity for using the whole bacterial cell to raise antiserum and provide a stable preparation which could be standardised.

\section{References}

' Skirrow MB. Campylobacter enteritis-a 'new' disease. Br Med J 1977;ii:9-11.

${ }^{2}$ Butzler JP, Skirrow MB. Campylobacter enteritis. Clin Gastroenterol 1979;8:737-65.

${ }^{3}$ George HA, Hoffman PS, Smibert RM, Krieg NR. Improved media for growth and aerotolerance of Campylobacter fetus. J Clin Microbiol 1978;8:36-41.

'Skirrow MB, Benjamin J. '1001' campylobacters: cultural characteristics of intestinal campylobacters from man and animals. J Hyg (Camb) 1980;85:427-42.

${ }^{5}$ Harvey SM. Hippurate hydrolysis by Campylobacter fetus. J Clin Microbiol 1980;11:435-7.

- Yeen WP, Puthucheary SD, Pang T. Demonstration of a cytotoxin from Campylobacter jejuni. J Clin Pathol 1983;36: $1237-40$.

' Johson WM, Lior H. Toxigenicity of Campylobacter jejuni and Campylobacter coli associated with human enteritis. In: Pearson DA, Skirrow MB, Rowe R, Davies JR, Jones DM, eds Campylobacter II. London: Public Health Laboratory Service, 1983:126.

${ }^{8}$ Wädstrom T, Baloda SB, Krovacek K, Faris A, Bengtson S, Walder M. Swedish isolates of Campylobacter jejuni/coli do not produce cytotonic or cytotoxic enterotoxins [letter]. Lancet 1983;ii:911.

${ }^{4}$ Karmall MA, Flemming PC. Campylobacter enteritis in children. J Pediatr 1979; 94:527-33.

${ }^{10}$ Paisley JW, Mirrett S, Lauer BA, Roe M, Reller LB. Dark-field microscopy of human faeces for presumptive diagnosis of Campylobacter fetus sub sp. jejuni enteritis. J Clin Microbiol 1982;15:61-3.

"Sazie ESM. Titus AE. Rapid diagnosis of campylobacter enteritis. Ann Intern Med 1982;96:62-3.

12 Park $\mathrm{CH}$, Hixton DL, Polhemus AS, et al. A rapid diagnosis of campylobacter enteritis by direct smear examination. Am J Clin Pathol 1983;80:388-90.

${ }^{13}$ Penner JL, Hennessy JN. Passive haemagglutination technique for serotyping Campylobacter fetus sub sp. jejuni on the basis of soluble heat-stable antigens. $J$ Clin Microbiol 1980;12:732-7.

${ }^{14}$ Lauwers S, Vlaes L, Butzler JP. Campylobacter serotyping and epidemiology. Lancet 1981;i:158-9.

is Lior H, Woodward DL, Edgar JA, Laroche LJ, Gill P. Serotyping of Campylobacter jejuni by slide agglutination based on heat-labile antigenic factors. J Clin Microbiol 1982;15:761-8.

${ }^{16}$ Abbott JD, Dale B, Eldridge J, Jones DM, Sutcliffe EM. Serotyping of Campylobacter jejuni/coli. J Clin Pathol 1980;33:762-6.

17 Kosunen TU, Danielsson D, Kjellander J. Serology of Campylobacter fetus ss. jejuni ("related" campylobacters). Acta Pathol Microbiol Immunol Scand [B] 1980;88:207-18.

${ }^{1 *}$ Blaser MJ, Craven J, Powers BW, Wang WL. Campylobacter enteritis associated wth canine infection. Lancet 1978;ii:27981.

${ }^{14}$ Watson KC, Kerr EJC. Some serological aspects of the diagnosis of campylobacter infection. In: Newell DG, ed. Campylobacter I. London: Public Health Laboratory Service, 1983:111-2.

${ }^{20}$ Lambe DW, Ferguson DA. Serology of Campylobacter jejuni by tube agglutination and fluorescent antibody methods. In Newell DG, ed. Campylobacter I. London: Public Health Laboratory Service, 1982:113-6.

${ }^{21}$ Skirrow MB. Session report on taxonomy and biotyping. In: Pearson AD, Skirrow MB, Rowe R, Davies JR, Jones DM, eds. Campylobacter II. London: Public Health Laboratory Service, 1982:36.

22 Jewkes J, Larson HE, Price AB, Sanderson PJ, Davies HA Aetiology of acute diarrhoea in adults. Gut 1981;22:388-92.

${ }^{23}$ Levine MM, Dupont HL, Formal SB, et al. Pathogenesis of Shigella dysentereae $I$ (Shiga) dysentery. J Infect Dis 1973; 127: 261-70.

${ }^{24}$ Turnbull PCB. Food poisoning with special reference to salmonella-its epidemiology, pathogenesis and control. Clin Gastroenterol 1979;8:663-714.

${ }^{25}$ Logan SM, Trust TJ. Outer membrane characteristics of Campylobacter jejuni. Infect Immun 1982;38:898-906.

${ }^{20}$ Naess V, Hofstad T. Isolation and chemical composition of lipopolysaccharide from Campylobacter jejuni. Acta Pathol Microbiol Immunol Scand [B] 1982;90:135-9.

${ }^{27}$ Rautelin $\mathrm{H}$, Kosunen TU. An acid extract as a common antigen in Campylobacter coli and Campylobacter jejuni strains.J Clin Microbiol 1983;17:700-1.

${ }^{28}$ Logan SM, Trust TJ. Molecular identification of surface protein antigens of Campylobacter jejuni. Infect Immun 1983; 42:675-82.

${ }^{29}$ Warren JR, Marshall B. Unidentified curved bacilli on gastric epithelium in active chronic gastritis. Lancet 1983;i:1273-5.

${ }^{30}$ Richi AE, Bryner JH, Foley JW. Role of DNA and bacteriophage in campylobacter auto-agglutination. J Med Microbiol 1983; 16:333-40.

Requests for reprints to: Dr A B Price, Consultant Histopathologist, Northwick Park Hospital, Watford Road, Harrow, Middlesex HA1 3UJ, England. 